\title{
Numerical simulation of 3D natural convection and entropy generation in a cubic cavity equipped with an adiabatic baffle
}

\author{
Kaouther Ghachem ${ }^{1}$, Walid Hassen ${ }^{1}$, Chemseddine Maatki ${ }^{1}$, Lioua Kolsi ${ }^{2,1^{*}}$, Abdullah A.A.A. Al-Rashed ${ }^{3}$, Mohamed Naceur \\ Borjini $^{1}$ \\ ${ }^{1}$ Unité de Recherche de Métrologie et des Systèmes Energétique, Ecole Nationale d'Ingénieurs, University of Monastir, \\ Monastir 5000, Tunisia \\ ${ }^{2}$ College of Engineering, Mechanical Engineering Department, Haïl University, Haïl 2240, Saudi Arabia \\ ${ }^{3}$ Department of Automotive and Marine Engineering Technology, College of Technological Studies, the Public Authority for \\ Applied Education and Training, Kuwait
}

Corresponding Author Email: lioua_enim@yahoo.fr

https://doi.org/10.18280/ijht.360335

Received: 14 October 2017

Accepted: 28 August 2018

\section{Keywords:}

FVM, 3D natural convection, baffle, entropy generation

\begin{abstract}
This paper presents a numerical study of natural convection and entropy generation in a cubic cavity fitted by a baffle plate. Three-dimensional analysis has been done by solving governing equations with a written computational code in FORTRAN based on FVM. The study was performed for two configurations related to the position of the baffle. The first one was carried for a baffle plate attached to the upper wall of the cavity although the second case was reserved for a baffle attached to the down face. The results are given for Rayleigh number $\left(\operatorname{Ra}=10^{5}\right)$, Prandtl number $(\operatorname{Pr}=7.1)$ and baffle length $(\mathrm{d}=0.5)$. The influences of baffle position on flow structure, temperature distribution, and heat transfer and entropy generation are presented.
\end{abstract}

\section{INTRODUCTION}

Several authors have studied the case of differentially heated cavity with one or more obstacles. A considerable amount of literature has been published to emphasize the effect induced by conductive or adiabatic obstacles on heat transfer.

Prakasha et al. [22], described the influence of the presence of an adiabatic baffle in a solar water storage tank. They showed that the performance of the storage device is improved by the addition of this baffle. The usefulness of the presence of the baffle has been demonstrated by comparing the studied configurations with and without obstacles. Surveys such as that conducted by Tiwari and Dhiman [26] have shown that the presence of a baffle in the hot water storage devices improves these performances essentially in the absence of solar energy. They also found that a shifted baffle near the absorber (i.e. the amount of water exposed to solar radiation is greater) allows a significant energy gain during night periods. Frederick [6] investigated numerically natural convection in an inclined differentially heated cavity containing a fin attached to the vertical cold wall. The Rayleigh number is varied between $10^{3}$ and $10^{5}$.The introduction of an obstacle causes the suppression of convection motion and a reduction of heat transfer up to $47 \%$ compared with the case without partition. A parametric study showing the effect of the Reynolds number, the length of the obstacle and its inclination on the improvement of heat transfer, was also presented. Bilgen [5] investigated numerically natural convection in an inclined differentially heated cavity containing a fin attached to the vertical hot wall. A parametric study was carried out by varying: the Rayleigh number between $10^{4}$ to $10^{9}$, the length of the fin between 0.1 and 0.9 and its position from 0 to 0.9 . The dimensionless conductivity of the fin varies between 0 and
60. The author has found that the Nusselt number increases with Rayleigh number and decreases according to the length and conductivity of the fin. To minimize convective transfer, the optimum position of the fin is identified near the center of the cavity. Later, Shi and Khodaddi [25] studied numerically the laminar natural convection in a differentially heated cavity containing a fin attached to the hot wall. The authors concluded that for high value of Rayleigh numbers, the heat transfer is improved irrespective of the position and the length of the fin. Bhave et al. [4] have proposed to improve the heat transfer in a differentially heated cavity by the addition of an adiabatic obstacle. They have changed obstacle size and then they studied the influence of variation of Prandlt number (three cases were tested: $0.0071,0.71$ and 7.1). In this work, the authors have defined a solidity coefficient as the ratio between the surface of the adiabatic obstacle and the total area of the cavity. Sheikhzadeh and Nikfar [23] studied the effect of aspect ratio on heat transfer and on the generation of entropy in an enclosure containing an adiabatic obstacle. Two fluids have been the subject of this investigation namely water and a nanofluid mixture (Cu-water). The tested values of the aspect ratio are: 1/3, 1/2, 1, 2 and 3 . The Rayleigh number has been varied from $10^{3}$ to $10^{6}$. The authors found that the use of nanofluid leads to an increase of the flow velocity, the Nusselt number and the generated entropy. However, the nanofluid minimizes the Bejan number essentially for strong Rayleigh numbers.

A recent numerical study by Kolsi et al. [13] allowed the calculation of the entropy generated according to the orientation of a fin placed in a cubic cavity. The physical model studied in this work is a cavity heated from below and cooled from the top while the vertical walls are adiabatic. A fin is located to left vertical wall to control heat and fluid flow. 
The effect of the conductivity "Rc" of the fin (0.1 to 100) and its inclination angle " $\theta$ " (-60 to 60$)$ were particularly examined. The authors indicated that the highest heat transfer is seen for the $-60^{\circ}$ of the fin angle and $\mathrm{Rc}=100$. Other interesting papers related to the subject can be found in the literature $[8.12,14-$ 17].

Mahian et al. [19] studied the entropy generation between two rotating cylinders with magnetohydrodynamic flow using nanofluids. They found that at low Brinkman numbers, the average entropy generation number decreases with the increase in nanoparticle volume fraction. They also found in [14] that when the contribution of viscous effects to entropy generation is adequately high for the base fluid $(\varphi=0)$, all models predict the increase of entropy generation with increases of particle loading.

Meibodi et al. [20] analyzed the entropy generation of a flatplate solar collector using $\mathrm{SiO}_{2}$ /ethylene glycol-water nanofluids. They found that the entropy generation parameter (founction of temperature, entropy generation and solar radiation) reduces with increasing the nanofluid concentration. Some other interesting results related to this subject can be found in literature $[1,9-10,21,28]$.

This paper presents the effect of the introduction of an adiabatic baffle on the fluid structure, heat transfer and entropy generation in $3 \mathrm{D}$ configurations related to the position and the thickness of the baffle.

\section{PHYSICAL MODEL AND COMPUTATIONAL STUDY}

The considered physical model is presented in Fig. 1. As seen from the figure, the cavity is differentially heated and a baffle is attached to top wall (configuration A) or to the bottom wall (configuration B). The baffle considered as adiabatic has a dimensionless thickness varying from 0.025 to 0.5 .

The $3 \mathrm{D}$ vorticity-vector potential formalism $(\vec{\psi}-\vec{\omega})$ isused as numerical method, in order to eliminate the pressure term, which is delicate to treat. $(\vec{\psi})$ and $(\vec{\omega})$ are respectively defined by the two following relations:

$$
\vec{\omega}^{\prime}=\vec{\nabla} \times \overrightarrow{u^{\prime}} \text { and } \vec{u}^{\prime}=\vec{\nabla} \times \vec{\psi}^{\prime}
$$

Equations controlling the phenomenon are written in the dimensionless form as follows:

$$
-\vec{\omega}=\nabla^{2} \vec{\psi}
$$

$\frac{\partial \vec{\omega}}{\partial t}+(\vec{u} \cdot \nabla) \vec{\omega}-(\vec{\omega} \cdot \nabla) \vec{u} \cdot=\Delta \vec{\omega}+\operatorname{Ra} \cdot \operatorname{Pr} \cdot\left[\frac{\partial T}{\partial z},-\frac{\partial T}{\partial x}, 0\right]$

$$
\frac{\partial T}{\partial t}+\vec{u} \cdot \nabla T=\nabla^{2} T
$$

$\operatorname{Pr}=\frac{v}{\alpha} \quad R a=\frac{g \beta\left(T_{h}-T_{c}\right) l^{3}}{v \cdot \alpha}$

The control volume finite difference method used to discretize equations (1) to (4). The central-difference scheme for treating convective terms and the fully implicit procedure to discretize the temporal derivatives are retained. The grid is uniform in all directions with additional nodes on boundaries. The successive relaxation iterating scheme is used to solve the resulting non-linear algebraic equations. The time step $10^{-4}$ and spatial mesh $81 \times 81 \times 81$ are retained to carry out all numerical tests. The solution is considered acceptable when the following convergence criterion is satisfied for each step of time as:

$\sum_{i}^{1,2,3} \frac{\max \left|\psi_{i}^{n}-\psi_{i}^{n-1}\right|}{\max \left|\psi_{i}^{n}\right|}+\max \left|T_{i}^{n}-T_{i}^{n-1}\right| \leq 10^{-5}$

where the superscript " $n$ " designates the nth iteration.

Boundary conditions for considered model are given as follows:

$\square$ Temperature boundary conditions

$T=0$ for $x=1$ and $T=1$ for $x=0$,

$\frac{\partial T}{\partial n}=0$ on all other walls (adiabatic).

$\square$ Vorticity

$\omega_{x}=0, \omega_{y}=-\frac{\partial u_{z}}{\partial x}, \omega_{z}=\frac{\partial u_{y}}{\partial x}$ at $x=0, x=0.5-t h / 2, x=$

$0.5+$ th $/ 2$ and $x=1$

$\omega_{x}=\frac{\partial u_{z}}{\partial y}, \omega_{y}=0, \omega_{z}=-\frac{\partial u_{x}}{\partial y}$ at $y=0 y=1$ and $y=d($ for

$0.5-t h / 2<x<0.5+t h / 2)$

$\omega_{x}=-\frac{\partial u_{y}}{\partial z}, \omega_{y}=\frac{\partial u_{x}}{\partial z}, \omega_{z}=0$ at $z=0$ and 1

$\square \quad$ Vector potential

$\frac{\partial \Psi_{x}}{\partial x}=\Psi_{y}=\Psi_{z}=0$ at $x=0, x=0.5-t h / 2, x=0.5+t h / 2$

and $x=1$

$\Psi_{x}=\frac{\partial \Psi_{y}}{\partial y}=\Psi_{z}=0$ at $y=0 \quad y=1$ and $y=d($ for $0.5-t h / 2<$

$x<0.5+t h / 2)$

$\Psi_{x}=\Psi_{y}=\frac{\partial \Psi_{z}}{\partial z}=0$ at $z=0$ and 1

$\square$ Velocity

$V_{x}=V_{y}=V_{z}=0$ at all walls

The generated entropy is written in the following form:

$S_{\text {gen }}^{\prime}=-\frac{1}{T^{\prime 2}} \cdot \vec{q} \cdot \vec{\nabla} T^{\prime}+\frac{\mu}{T^{\prime}} \cdot \varphi^{\prime}$

The first term represents the generated entropy due to temperature gradient and the second that due to the friction effects.

$\vec{q}=-k \cdot g r a \vec{d} T$

The dissipation function is written in incompressible flow as:

$$
\begin{aligned}
& \varphi^{\prime}=2\left[\left(\frac{\partial V_{x}^{\prime}}{\partial x^{\prime}}\right)^{2}+\left(\frac{\partial V_{y}^{\prime}}{\partial y^{\prime}}\right)^{2}+\left(\frac{\partial V_{z}^{\prime}}{\partial z^{\prime}}\right)^{2}\right] \\
& +\left(\frac{\partial V_{y}^{\prime}}{\partial x^{\prime}}+\frac{\partial V_{x}^{\prime}}{\partial y^{\prime}}\right)^{2}+\left(\frac{\partial V_{z}^{\prime}}{\partial y^{\prime}}+\frac{\partial V_{y}^{\prime}}{\partial z^{\prime}}\right)^{2}+\left(\frac{\partial V_{x}^{\prime}}{\partial z^{\prime}}+\frac{\partial V_{z}^{\prime}}{\partial x^{\prime}}\right)^{2}
\end{aligned}
$$


from where the generated entropy is written as:

$$
\begin{aligned}
& S_{\text {gen }}^{\prime}=\frac{k}{T_{0}^{\prime 2}}\left[\left(\frac{\partial T^{\prime}}{\partial x^{\prime}}\right)^{2}+\left(\frac{\partial T^{\prime}}{\partial y^{\prime}}\right)^{2}+\left(\frac{\partial T^{\prime}}{\partial z^{\prime}}\right)^{2}\right] \\
& +2\left[\left(\frac{\partial V_{x}^{\prime}}{\partial x^{\prime}}\right)^{2}+\left(\frac{\partial V_{y}^{\prime}}{\partial y^{\prime}}\right)^{2}+\left(\frac{\partial V_{z}^{\prime}}{\partial z^{\prime}}\right)^{2}\right] \\
& +\left(\frac{\partial V_{y}^{\prime}}{\partial x^{\prime}}+\frac{\partial V_{x}^{\prime}}{\partial y^{\prime}}\right)^{2}+\left(\frac{\partial V_{z}^{\prime}}{\partial y^{\prime}}+\frac{\partial V_{y}^{\prime}}{\partial z^{\prime}}\right)^{2}+\left(\frac{\partial V_{x}^{\prime}}{\partial z^{\prime}}+\frac{\partial V_{z}^{\prime}}{\partial x^{\prime}}\right)^{2}
\end{aligned}
$$

The dimensionless local generated entropy $\left(\mathrm{N}_{\mathrm{S}}\right)$ is written in the following way:

$N_{s}=S_{\text {gen }}^{\prime} \frac{1}{k}\left(\frac{l T_{0}}{\Delta T}\right)^{2}$

From where:

$$
\begin{aligned}
& N_{s}=\left[\left(\frac{\partial T}{\partial x}\right)^{2}+\left(\frac{\partial T}{\partial y}\right)^{2}+\left(\frac{\partial T}{\partial z}\right)^{2}\right] \\
& +\phi .\left\{\begin{array}{l}
2\left[\left(\frac{\partial V_{x}}{\partial x}\right)^{2}+\left(\frac{\partial V_{y}}{\partial y}\right)^{2}+\left(\frac{\partial V_{z}}{\partial z}\right)^{2}\right] \\
+\left[\left(\frac{\partial V_{y}}{\partial x}+\frac{\partial V_{x}}{\partial y}\right)^{2}+\left(\frac{\partial V_{z}}{\partial y}+\frac{\partial V_{y}}{\partial z}\right)^{2}+\left(\frac{\partial V_{x}}{\partial z}+\frac{\partial V_{z}}{\partial x}\right)^{2}\right]
\end{array}\right\}
\end{aligned}
$$

with $\phi=\frac{\mu \alpha^{2} T_{m}}{l^{2} k \Delta T^{2}}$ is the irreversibility coefficient.
The first term of $\mathrm{N}_{\mathrm{s}}$ represents the local irreversibility due to the temperatures gradients, it is noted $\mathrm{N}_{\mathrm{S} \text {-th. }}$ The second term represents the contribution of the viscous effects in the irreversibility it is noted $\mathrm{N}_{\mathrm{S} \text {-fric. }} \mathrm{N}_{\mathrm{s}}$ give a good idea on the profile and the distribution of the generated local dimensionless entropy. The total dimensionless generated entropy is written:

$S_{t o t}=\int_{0}^{1} \int_{0}^{1} \int_{0}^{1} N_{s} d v=\int_{0}^{1} \int_{0}^{1} \int_{0}^{1}\left(N_{s-t h}+N_{s-f r}\right) d v=S_{t h}+S_{f r}$

Bejan number $(\mathrm{Be})$ is the ratio of heat transfer irreversibility to the total irreversibility due to heat transfer and fluid friction:

$B e=\frac{S_{t h}}{S_{t h}+S_{f r}}$

The local and average Nusselt at the cold wall are given by:

$\mathrm{N} u=\left.\frac{\partial T}{\partial x}\right|_{x=1}$ and $\mathrm{N} u_{a v}=\int_{00}^{1} \int_{0}^{1} N u \partial y \partial z$

\section{VERIFICATION OF THE CODE}

The verification of the code is performed against data in published studies. Thus, results are compared with works of Wakashima and Saitho [27] and Fusegi et al. [7] for

\begin{tabular}{|c|c|c|c|c|c|c|}
\hline $\mathrm{Ra}$ & Authors & $\begin{array}{c}\psi_{z} \\
\text { (center) }\end{array}$ & $\begin{array}{c}\omega_{z} \\
\text { (center) }\end{array}$ & $\begin{array}{c}V_{x \max } \\
(\mathrm{y})\end{array}$ & $\begin{array}{c}V_{y \max } \\
(\mathrm{x})\end{array}$ & $N u_{a v}$ \\
\hline \multirow[t]{3}{*}{$10^{4}$} & Presentwork & 0.05528 & 1.1063 & $\begin{array}{c}0.199 \\
(0.826) \\
\end{array}$ & $\begin{array}{c}0.221 \\
(0.112) \\
\end{array}$ & 2.062 \\
\hline & $\begin{array}{c}\text { Wakashima and } \\
\text { Saitho(2004) }\end{array}$ & 0.05492 & 1.1018 & $\begin{array}{c}0.198 \\
(0.825) \\
\end{array}$ & $\begin{array}{c}0.222 \\
(0.117) \\
\end{array}$ & 2.062 \\
\hline & Fusegi et al. (1991) & --- & --- & $\begin{array}{c}0.201 \\
(0.817) \\
\end{array}$ & $\begin{array}{c}0.225 \\
(0.117) \\
\end{array}$ & 2.1 \\
\hline \multirow[t]{3}{*}{$10^{5}$} & Presentwork & 0.034 & 0.262 & $\begin{array}{c}0.143 \\
(0.847) \\
\end{array}$ & $\begin{array}{c}0.245 \\
(0.064) \\
\end{array}$ & 4.378 \\
\hline & $\begin{array}{c}\text { Wakashima and } \\
\text { Saitoh(2004) }\end{array}$ & 0.03403 & 0,2573 & $\begin{array}{l}0.147 \\
(0.85) \\
\end{array}$ & $\begin{array}{c}0.246 \\
(0.068) \\
\end{array}$ & 4.366 \\
\hline & Fusegi et al. (1991) & --- & --- & $\begin{array}{c}0.147 \\
(0.855) \\
\end{array}$ & $\begin{array}{c}0.247 \\
(0.065)\end{array}$ & 4.361 \\
\hline \multirow[t]{3}{*}{$10^{6}$} & Presentwork & 0.01972 & 0.1284 & $\begin{array}{l}0.0832 \\
(0.847)\end{array}$ & $\begin{array}{c}0.254 \\
(0.032)\end{array}$ & 8.618 \\
\hline & $\begin{array}{c}\text { Wakashima and } \\
\text { Saitho(2004) }\end{array}$ & 0.01976 & 0.1366 & $\begin{array}{c}0.0811 \\
(0.86) \\
\end{array}$ & $\begin{array}{l}0.2583 \\
(0.032) \\
\end{array}$ & 8.6097 \\
\hline & Fusegi et al. (1991) & --- & --- & $\begin{array}{l}0.0841 \\
(0.856)\end{array}$ & $\begin{array}{c}0.259 \\
(0.033)\end{array}$ & 8.77 \\
\hline
\end{tabular}
differentially heated cubic cavity filled with a fluid of $\operatorname{Pr}=0.71$. The results presented in Table 1 show a good agreement with the earliest studies.

Table 1. Code verification

\section{RESULTS AND DISCUSSION}

The configuration studied in this paper consists in a $3 \mathrm{D}$ cubic cavity with a baffle plate attached in the first configuration (A) to the upper adiabatic wall and in the second configuration (B) to the lower one (Fig. 1). The left side wall of the cavity is maintained at hot temperature Th and its right side wall at cold temperature Tc. The other walls considered adiabatic. The effects of the position and the thickness of the baffle plate are presented for a fixed Rayleigh number $\mathrm{Ra}=$ 105, Prandtl number $\operatorname{Pr}=7.1$ and a baffle length $d=0.5$.

Figures 2 and 3, present the effect of the baffle thickness 
variation on the z-component of vector potential and on particles trajectories.

From these figures, and by opposition to the 2D case, the particles trajectories are not closed and there is a passage from a constant z-plan to another. The presence of the baffle plate affects to a large degree the flow structure. In fact, there is no central symmetry. This dissymmetry is more important by increasing the baffle thickness. The flow is characterized by one cell with two or three vortex depending on the thickness of the baffle and turning in the clockwise circulation. For th $=$ 0.5 , the flow structure is characterized by two main vortexes. One of them is located at the left part and the other under the baffle. When the baffle thickness is decreasing, a dissociation of the bottom vortex occurs for th $=0.3$. For this case, the flow structure characterized by three main vortexes: tow under the baffle and one near the left-high corner. For lower values of th, a coalescence of tow vortexes occurs and flow structure remains with two vortexes localized both under the baffle.

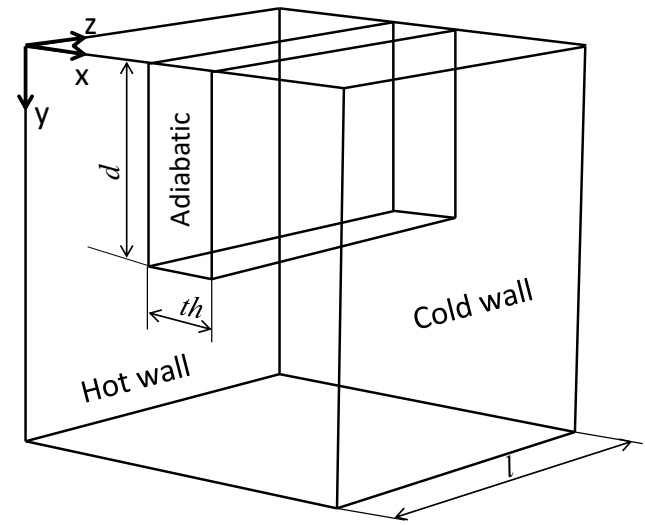

(A)

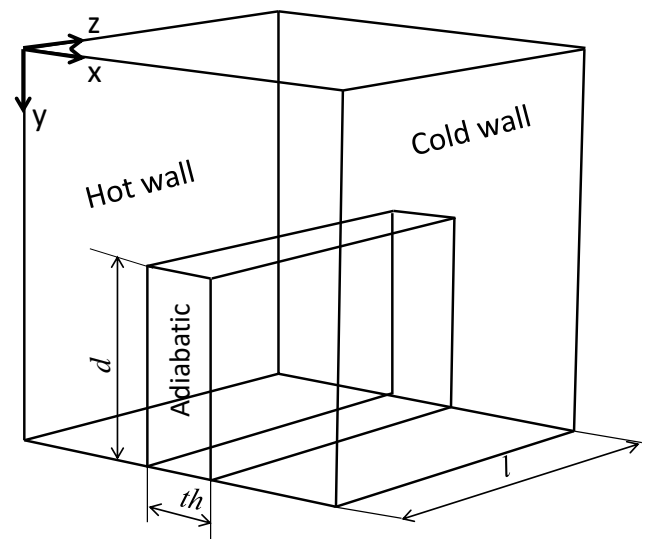

(B)

Figure 1. Studied cases, (A): first configuration and (B) second configuration

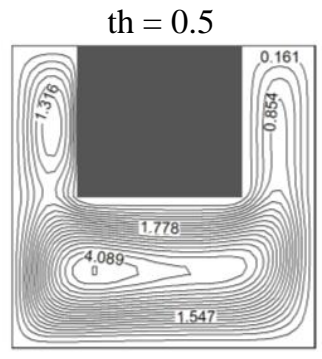

$\Psi_{\max }=4.32$

th $=0.1$ th $=0.3$

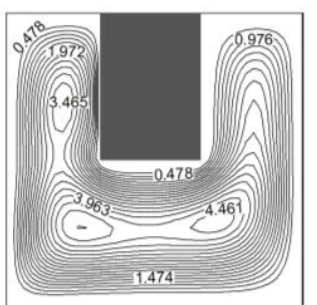

$\Psi_{\max }=4.75$

th $=0.025$

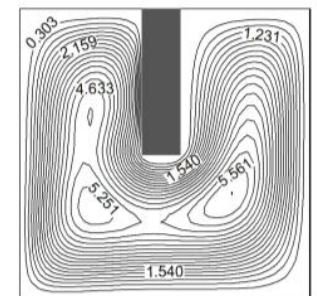

$\Psi_{\max }=5.87$

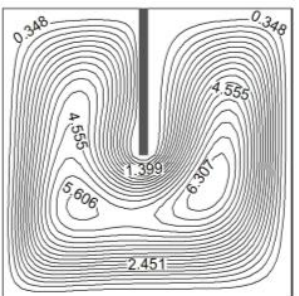

$\Psi_{\max }=6.48$
Figure 2. Plots of $\mathrm{z}$-vector potential component at $\mathrm{z}=0.5$ plan for different thickness of the baffle connected to the upper wall of the cavity

Figure 4 presents the isosurfaces of temperature and the isotherm lines at $\mathrm{z}=0.5$ plan for different "th" values. Regardless the baffle thickness, a high thermal gradient located near the lower part of the hot wall is observed. Between the hot wall and the baffle, a conductive regime is noted for a thickness equal to 0.5. The most important characteristic of this regime is the presence of parallel isothermal surfaces. However, the reducing of the baffle thickness marks a transition to a convective regime. In this case, the distortions of isothermal surfaces become more important.
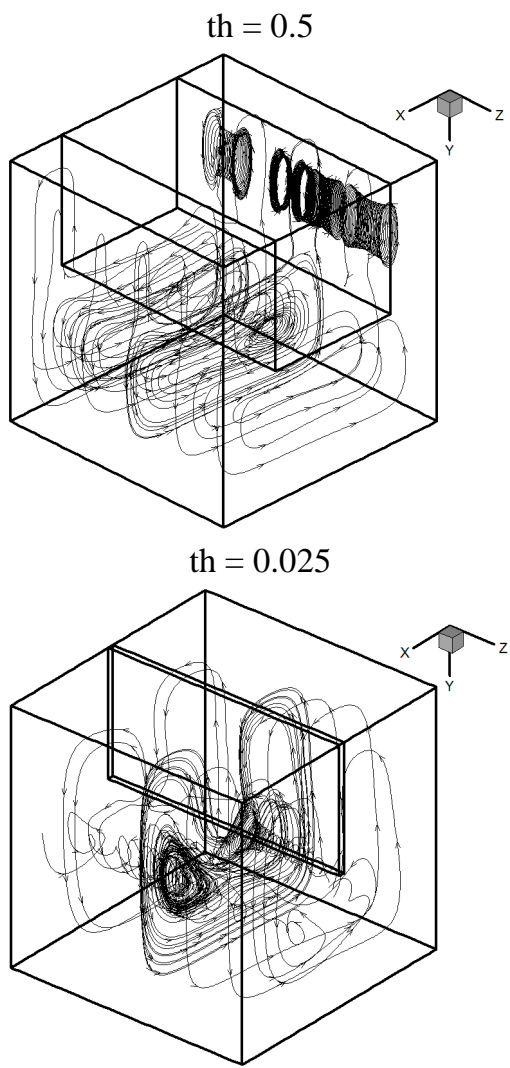

Figure 3. Some particles trajectory for different thickness of the baffle (configuration $\mathrm{A}$ )

At the lower area of the cavity (below the baffle), it is clearly seen that the convective regime is not affected by the thickness of the obstacle. Indeed, the distortions of the isothermal surfaces were found for all studied configurations.

Figure 5 shows the velocity projection in $\mathrm{z}=0.5$ plan for different thickness of the baffle. The description of the velocity field distribution shows the existence of three zones, as follows: 
$\square$ Zone 1: above the baffle

For a baffle thickness equal to 0.5 (Figure 5), the flow is characterized by one cell with a single vortex located near the cold wall. A birth of a second counter rotating vortex was observed when the thickness of this obstacle is 0.3 . When th is equal to 0.1 , the vortex situated at the left of the baffle, is more stretched towards the bottom of the cavity (on the side of the hot wall).

$\square$ Zone 2: between the hot wall of the cavity and the left wall of the baffle

This area is characterized by the development of a clockwise rotating vortex. We note that the reduction of the thickness of the baffle is accompanied by the decreases of this vortex until disappearance at 0.025 . However, we see the emergence of a counter-rotating vortex close to the baffle wall.

In addition, it is noted the existence of a dynamic boundary layer around the baffle, which generates a significant change in the flow topography. Due to the effects of the fluid friction near the baffle walls, a coalescence of the two vortices was noticed forth $=0.1$ and th $=0.025$.

$\square$ Zone 3: between the cold wall of the cavity and the right wall of the baffle
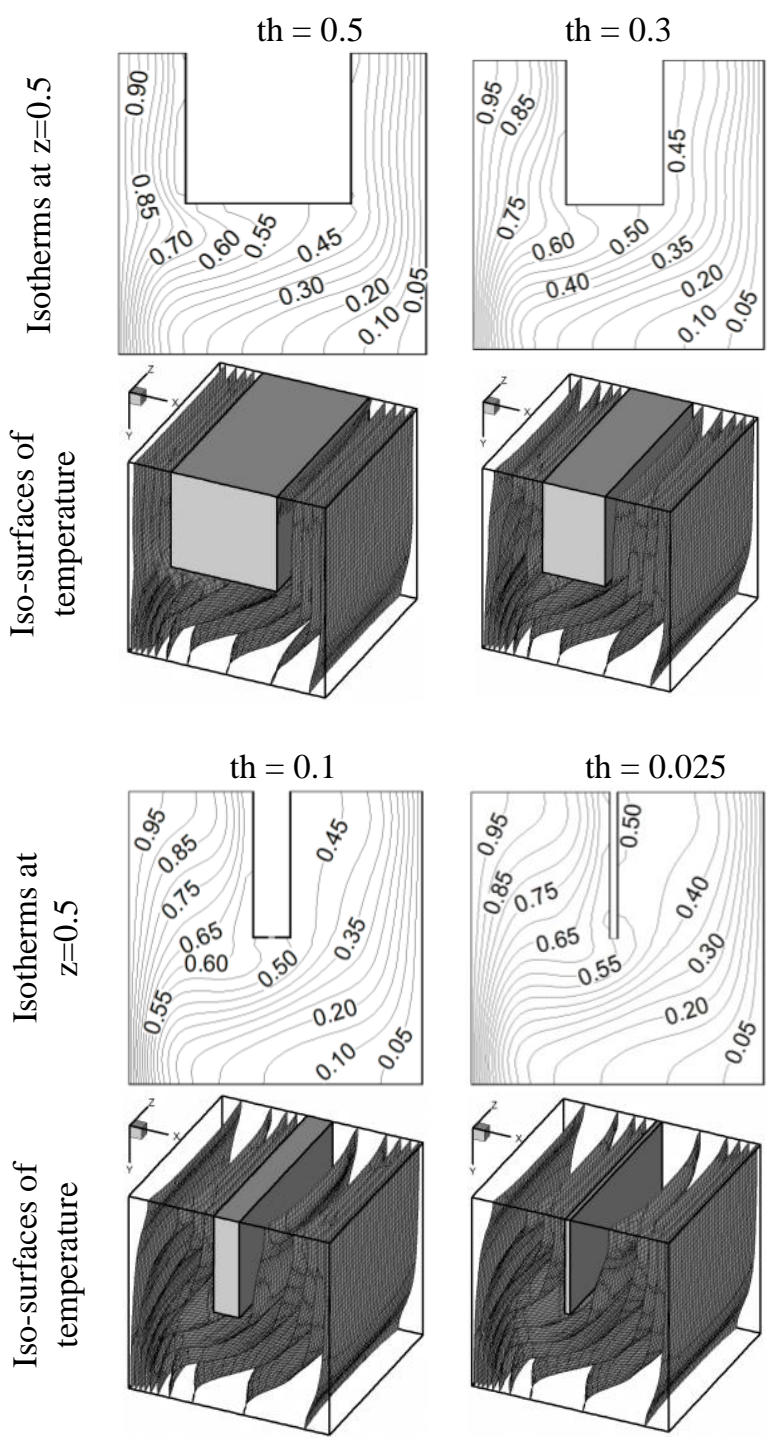

Figure 4. Isotherm at $\mathrm{z}=0.5$ plan and iso-surfaces of temperature for different baffle thickness (configuration $\mathrm{A}$ )
In this third area, for th equal to 0.5 , a clockwise rotating cell takes place but as soon as the thickness of the baffle decreases this cell disappears.

Figure 6 shows the temperature iso-contours when the baffle is connected to the lower adiabatic wall. By decreasing the thickness of the baffle, an intensification of the thermal gradient is mentioned in the upper part of the cold wall. For a baffle thickness equal to 0.5 , a conductive regime, characterized by parallel isotherm, takes place at the bottom of the hot wall. For the configuration B, the lower area next the hot wall becomes larger and a development of the convective regime on both sides of baffle is noticed.

Figure 7 shows the variation of the Nusselt number on the hot wall according to the thickness of the baffle. It is clear that the heat transfer rate is better for configuration $\mathrm{A}$.

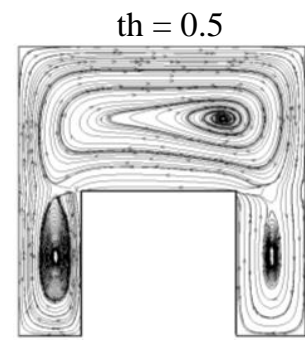

th $=0.1$

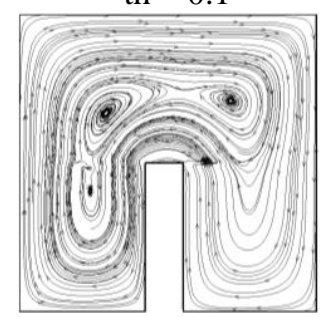



th $=0.025$

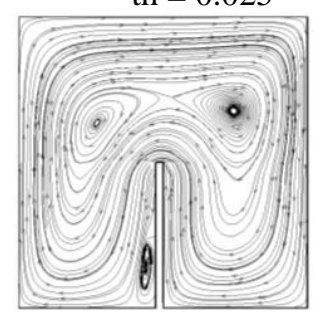

Figure 5. Velocity vector projection at $\mathrm{z}=0.5$ plan for different th

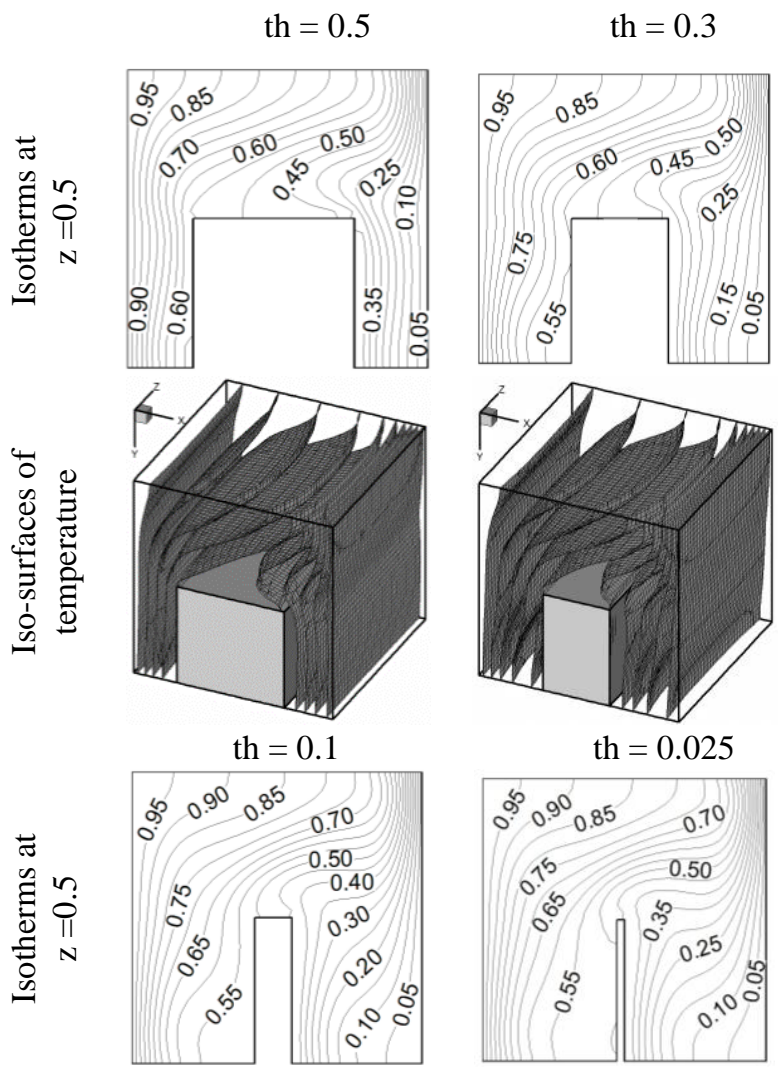



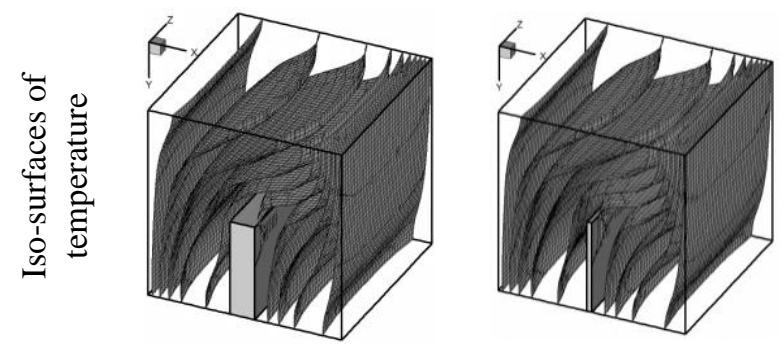

Figure 6. Isothermsand Iso-surfaces of temperature for different baffle thickness (configuration B)

Maximum heat transfer detected for a minimum thickness of the baffle, which connected to the upper surface of the cavity. Otherwise, if the baffle is connected to the upper surface, the transfer is highest at the largest thickness $($ th $=0.5)$ Finally, some conclusions can be drawn as follows:

- For a baffle connected to the upper surface: Reducing the thickness "th" improves the heat exchange rate. In fact, a variation of "th" from 0.5 to 0.025 generates an enhancement of heat transfer equal to $11.58 \%$.

- For a baffle connected to the lower surface: :

$\checkmark$ Maximum heat exchange is identified for a thickness equal to 0.5

$\checkmark$ Reducing the thickness of the baffle from 0.5 to 0.3 , creates a decrease of the heat exchange rate equal to $12.25 \%$

$\checkmark \quad$ Both thickness th $=0.1$ and th $=0.025$ have almost the same heat exchange rate however they present a slight improvement of the heat transfer $(6.28 \%)$ compared with th $=0.3$

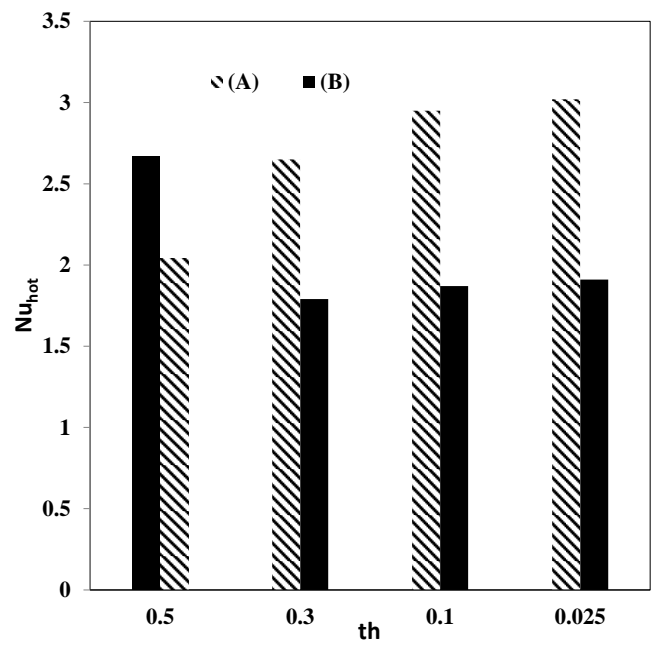

Figure 7. Variation of the hot Nusselt number versus baffle thickness

Computations are carried out for a fixed irreversibility coefficient $\varphi=10^{-4}$. The variations of the average value of the thermal, viscous and total entropy are presented in Figures (8, 9 and 10).

Whatever the position of the baffle, the value of the average thermal entropy decreases by reducing the thickness "th" (Figure 8). Slightly higher value of the thermal entropy was detected for configuration A.

Regarding the average viscous entropy (figure 9), higher mean values were observed for configuration A. In this configuration, the maximum value is identified for a thickness equal to 0.1 , while the minimum is for th $=0.025$. A decrease in the average viscous entropy by $29 \%$ for a variation of thickness from 0.025 to 0.1 is noted.

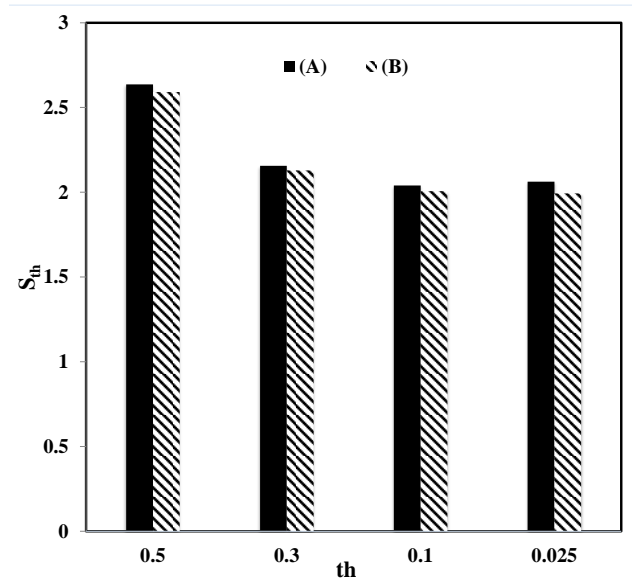

Figure 8. Effect of baffle thickness on average thermal entropy

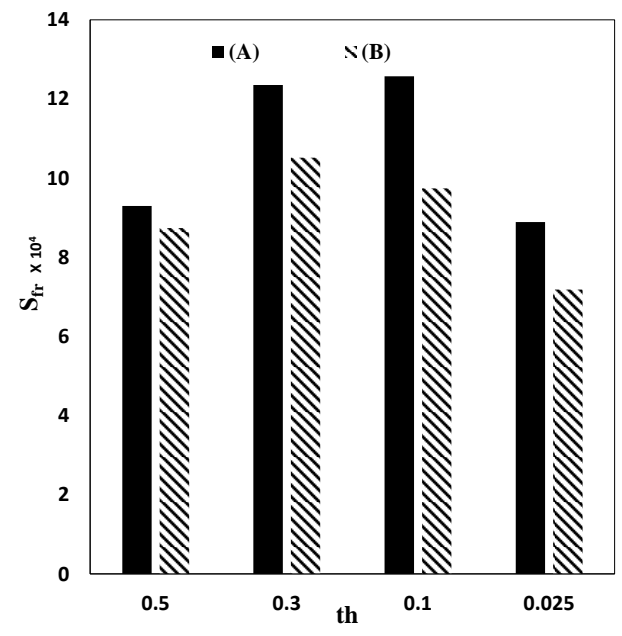

Figure 9. Effect of baffle thickness on average viscous entropy

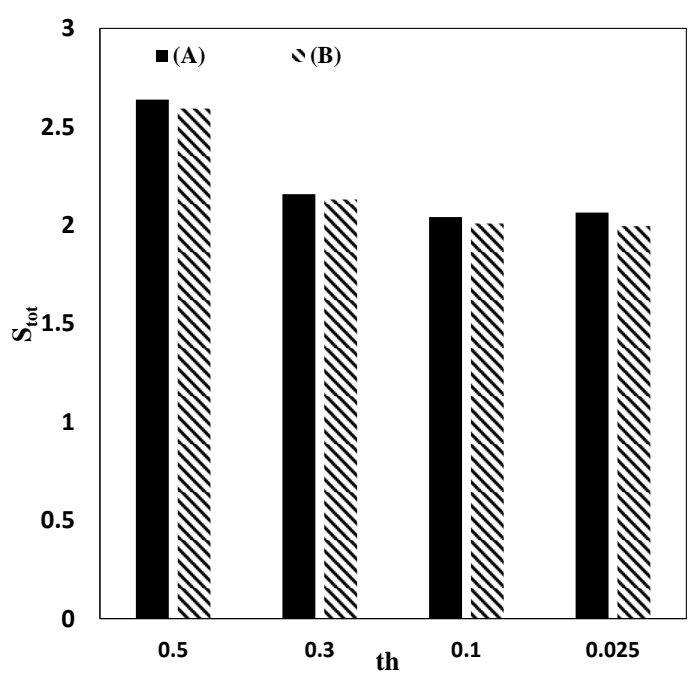

Figure 10. Effect of baffle thickness on average total entropy

Likewise, for configuration $\mathrm{B}$, the maximum viscous entropy is identified for a thickness equal to 0.3 , while the minimum is always for th $=0.025$ (a decrease of $31.67 \%$ ). 


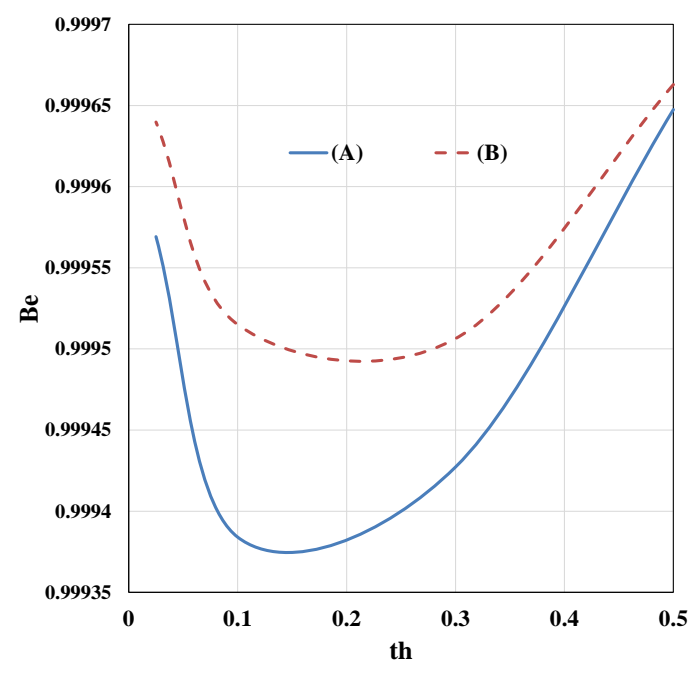

Figure 11. Effect of baffle thickness on Bejan number

The evolution of the average total entropy is given by Figure 10. Since the viscous entropy is negligible compared to the thermal entropy, a strong similarity between the two Figures 8 and 10 is observed. This similarity is supported by the variation of Bejan number (figure 11) which is almost near of the unity indicating the dominance of the entropy generated due to viscous effects.

\section{CONCLUSIONS}

In the present work, we focused on the effect of the introduction of a baffle in a differentially heated threedimensional cavity. Particular attention regarding the estimation of the entropy generation was granted. Different patterns of flow were observed with changing the thickness and the position of the baffle. The main findings of the present investigation are summarized as follows:

- for configuration A

- The flow structure is strongly modified by varying the thickness of the baffle from 0.025 to 0.5 .

$\circ \quad$ Inside the space between the baffle and the bottom wall of the cavity, we noticed a change in the topography of the flow. In fact, a variation in the number and position of the vortex according to the thickness of the baffle was clearly noted.

O Between the hot wall of the cavity and the baffle, a birth of a convective cell appears by increasing the thickness "th" to 0.5 .

for configuration $\mathrm{B}$

$\circ$ Reducing the thickness of the baffle promotes the conversion from a conductive regime (characterized by parallel temperature iso-contours) towards a convective regime (characterized by a distortion of temperature iso-contours)

- The temperature distribution in the lower part of the wall remains almost the same whatever the dimensions of the baffle.

\section{REFERENCES}

[1] Mahian O, Kianifar A, Kleinstreuer C, Al-Nimr MA, Pop I, Sahin AZ, Wongwises S. (2013). A review of entropy generation in nanofluid flow. International Journal of
Heat and Mass Transfer 65: 514-532. https://doi.org/10.1016/j.ijheatmasstransfer.2013.06.010

[2] Abidi A, Kolsi L, Borjini MN, Ben Aissia H. (2011). Effect of radiative heat transfer on three-dimensional double diffusive natural convection. numer. Heat Transf. Part Appl. 60: 785-809. https://doi.org/10.1080/10407782.2011.627797

[3] Al-Rashed AAAA, Kalidasan K, Kolsi L, Borjini MN, Kanna PR. (2017). Three-dimensional natural convection of CNT-water nanofluid confined in an inclined enclosure with Ahmed body. J. Therm. Sci. Technol. 12: JTST0002-JTST0002. https://doi.org/10.1299/jtst.2017jtst0002

[4] Bhave P, Narasimhan A, Rees DAS. (2006). Natural convection heat transfer enhancement using adiabatic block: Optimal block size and Prandtl number effect. Int. J. Heat Mass Transf. 49: 3807-3818. https://doi.org/10.1016/j.ijheatmasstransfer.2006.04.017

[5] Bilgen E. (2005). Natural convection in cavities with a thin fin on the hot wall. Int. J. Heat Mass Transf. 48: 3493-3505.

https://doi.org/10.1016/j.ijheatmasstransfer.2005.03.016

[6] Frederick RL. (1989). Natural convection in an inclined square enclosure with a partition attached to its cold wall. Int. J. Heat Mass Transf. 32: 87-94. https://doi.org/10.1016/0017-9310(89)90093-8

[7] Fusegi T, Hyun JM, Kuwahara K, Farouk B. (1991). A numerical study of three-dimensional natural convection in a differentially heated cubical enclosure. Int. J. Heat Mass Transf. 34: 1543-1557. https://doi.org/10.1016/0017-9310(91)90295-P

[8] Ghachem K, Kolsi L, Maatki C, Alghamdi A, Oztop HF, Borjini MN, Ben Aissia H, Al-Salem K. (2016). Numerical simulation of three-dimensional double diffusive convection in a lid-driven cavity. Int. J. Therm. Sci. 110 : 241-250. https://doi.org/10.1016/j.ijthermalsci.2016.07.004

[9] Ho CJ, Chen DS, Yan WM, Mahian O. (2014). Rayleigh-Bénard convection of A12O3/water nanofluids in a cavity considering sedimentation, thermophoresis, and Brownian motion. Int. Commun. Heat Mass Transf. 57: $22-26$. https://doi.org/10.1016/j.icheatmasstransfer.2014.07.01 4

[10] Jashim Uddin Md, Fazlul Hoque AKM. (2018). Convective heat transfer flow of nanofluid in an isosceles triangular shaped enclosure with an uneven bottom wall. Chemical Engineering Transactions 66: 403-408. https://doi.org/10.3303/CET1866068

[11] Kaushik SC, Kumar R, Garg HP. (1995). Effect of baffle plate on the performance of a triangular built-in-storage solar water heater. Energy Convers. Manag. 36: 337342. https://doi.org/10.1016/0196-8904(95)98898-W

[12] Kolsi L. (2016). Numerical analysis of periodic 3D convective heat transfer in fenestration with betweenthe-glass louvered blinds. Case Stud. Therm. Eng. 8: 7183. https://doi.org/10.1016/j.csite.2016.05.002

[13] Kolsi L, Abu-Hamdeh N, Öztop HF, Alghamdi A, Borjini MN, Ben Assia H. (2016a). Natural convection and entropy generation in a three dimensional volumetrically heated and partially divided cavity. Int. J. Numer. Methods Heat Fluid Flow 26: 2492-2508. https://doi.org/10.1108/HFF-09-2015-0358

[14] Kolsi L, Kalidasan K, Alghamdi A, Borjini MN, Kanna 
PR. (2016b). Natural convection and entropy generation in a cubical cavity with twin adiabatic blocks filled by aluminum oxide-water nanofluid. Numer. Heat Transf. $\begin{array}{lll}\text { Part } & \text { Appl. 242-259. }\end{array}$ https://doi.org/10.1080/10407782.2016.1173478

[15] Kolsi L, Mahian O, Öztop HF, Aich W, Borjini MN, Abu-Hamdeh N, Aissia HB. (2016c). 3D buoyancyinduced flow and entropy generation of nanofluid-filled open cavities having adiabatic diamond shaped obstacles. $\quad$ Entropy 232. https://doi.org/10.3390/e18060232

[16] Kolsi L, Oztop HF, Abu-Hamdeh N, Alghamdi A, Naceur Borjini MN. (2016d). Three dimensional analysis of natural convection and entropy generation in a sharp edged finned cavity. Alex. Eng. J. 55: 991-1004. https://doi.org/10.1016/j.aej.2016.02.030

[17] Kolsi L, Oztop HF, Alghamdi A, Abu-Hamdeh N, Borjini MN, Ben Aissia H. (2016e). A computational work on a three dimensional analysis of natural convection and entropy generation in nanofluid filled enclosures with triangular solid insert at the corners. J. Mol. Liq. 218: 260-274 https://doi.org/10.1016/j.molliq.2016.02.083

[18] Maatki C, Ghachem K, Kolsi L, Borjini N, Aissia HB. (2013). Entropy generation of double diffusive natural convection in a three dimensional differentially heated enclosure. Int. J. Eng. - Trans. B Appl. 27: 215.

[19] Mahian O, Mahmud S, Zeinali Heris S. (2012). Effect of uncertainties in physical properties on entropy generation between two rotating cylinders with nanofluids. J. Heat Transf. 134: 101704. https://doi.org/10.1115/1.4006662

[20] Meibodi SS, Kianifar A, Mahian O, Wongwises S. (2016). Second law analysis of a nanofluid-based solar collector using experimental data. J. Therm. Anal. Calorim. 126: 617-625. https://doi.org/10.1007/s10973016-5522-7

[21] Mahian O, Kianifar A, Heris SZ, Wongwises S. (2016). Natural convection of silica nanofluids in square and triangular enclosures: Theoretical and experimental study. International Journal of Heat and Mass Transfer, 99: 792-804. https://doi.org/10.1016/j.ijheatmasstransfer.2016.03.045

[22] Prakash J, Garg HP, Datta G. (1983). Effect of baffle plate on the performance of built-in storage type solar water heater. Energy 8: 381-387. https://doi.org/10.1016/0360-5442(83)90088-9

[23] Sheikhzadeh GA, Nikfar M. (2013). Aspect ratio effects of an adiabatic rectangular obstacle on natural convection and entropy generation of a nanofluid in an enclosure. J. Mech. Sci. Technol. 27: 3495-3504. https://doi.org/10.1007/s12206-013-0875-3

[24] Sheikhzadeh GA, Nikfar M, Fattahi A. (2012). Numerical study of natural convection and entropy generation of $\mathrm{Cu}$-water nanofluid around an obstacle in a cavity. J. Mech. Sci. Technol. 26: 3347-3356. https://doi.org/10.1007/s12206-012-0805-9

[25] Shi X, Khodadadi JM. (2003). Laminar natural convection heat transfer in a differentially heated square cavity due to a thin fin on the hot wall. J. Heat Transf. 125: 624-634. https://doi.org/10.1115/1.1571847

[26] Tiwari GN, Dhiman NK. (1983). Effect of the baffle plate on transient performance of built-in-storage water heater. Energy Convers. Manag. 23: 151-155. https://doi.org/10.1016/0196-8904(83)90058-4

[27] Wakashima S, Saitoh TS. (2004). Benchmark solutions for natural convection in a cubic cavity using the highorder time-space method. Int. J. Heat Mass Transf. 47: 853-864.

https://doi.org/10.1016/j.ijheatmasstransfer.2003.08.008

[28] Wernik J, Grabowski M, Wołosz KJ. (2018). Thermal analysis of radiator under natural and forced convection conditions using numerical simulation and thermography. Chemical Engineering Transactions 70: 1501-1506. https://doi.org/10.3303/CET1870251

\section{NOMENCLATURE}

$\begin{array}{ll}\mathrm{Be} & \begin{array}{l}\text { Bejan number } \\ \mathrm{k}\end{array} \\ N_{s} & \text { thermal conductivity }\left[\mathrm{W} \cdot \mathrm{m}^{-1} \cdot \mathrm{K}^{-1}\right] \\ \mathrm{Pr} & \text { Prandtl number } \\ \vec{q}^{\prime} & \text { Heat flux vector } \\ \mathrm{Ra} & \text { Rayleigh number } \\ S^{\prime}{ }_{g e n} & \text { Generated entropy } \\ \mathrm{S}_{\mathrm{th}} & \text { Thermal entropy generation } \\ \mathrm{S}_{\mathrm{fr}} & \text { Viscous entropy generation } \\ \mathrm{S}_{\mathrm{tot}} & \text { Total entropy generation } \\ \mathrm{t} & \text { dimensionless time }\left(=t^{\prime} \cdot \alpha / l^{2}\right) \\ \mathrm{th} & \text { baffle thickness } \\ \mathrm{T}^{2} & \text { dimensionless temperature }[= \\ \left.\left(T^{\prime}-T^{\prime}{ }_{c}\right) /\left(T^{\prime}{ }_{h}-T^{\prime}{ }_{c}\right)\right] \\ T^{\prime}{ }_{c} & \text { Cold temperature }[\mathrm{K}] \\ T^{\prime}{ }_{h} & \text { Hot temperature }[\mathrm{K}] \\ \text { th } & \text { Dimensionless thickness }(=\text { th' } / 1) \\ \vec{V} & \text { Dimensionless velocity vector }\left(=\vec{V}^{\prime} . l / \alpha\right)\end{array}$

\section{Greek symbols}

$\alpha$

$\beta$

$\mu$

$v$

$v_{0}$

$\phi$

$\varphi^{\prime}$

$\vec{\psi}$

$\vec{\omega}$

\section{Subscripts}

$\begin{array}{ll}\text { av } & \text { average } \\ \text { fr } & \text { friction } \\ \text { th } & \text { thermal } \\ \text { tot } & \text { total } \\ \mathrm{x}, \mathrm{y}, \mathrm{z} & \text { Cartesian coordinates }\end{array}$

\section{Superscript}

\author{
Thermal diffusivity $\left[\mathrm{m}^{2} \cdot \mathrm{s}^{-1}\right]$ \\ Expansion coefficient $\left[\mathrm{K}^{-1}\right]$ \\ Dynamic viscosity [Pa.s] \\ Kinematic viscosity $\left[\mathrm{m}^{2} . \mathrm{s}^{-1}\right]$ \\ Characteristic speed of fluid $(=\alpha / l)$ \\ Irreversibility coefficient \\ Dissipation function \\ Dimensionless vector potential $\left(\vec{\psi}^{\prime} / \alpha\right)$ \\ Dimensionless vorticity $\left(=\vec{\omega}^{\prime} . \alpha / l^{2}\right)$
}

